Abstract ID: 44

\title{
Correlation between schroeder-phase effect and electrocochleography findings
}

\author{
Solihatul Mardhiah Muhamad Azman | Sarah Rahmat \\ Department of Audiology \& Speech-Language Pathology, Kulliyyah of Allied Health Sciences, \\ International Islamic University Malaysia
}

Introduction: In Schroeder-phase masking test, different auditory perception ability towards different phases of Schroeder masker is known as 'phase effect'. Previously, the phase effect mechanism was proposed to be dominantly contributed by peripheral auditory function, mainly by outer hair cells. This study aims to investigate the possible involvement of central auditory function (i.e. auditory nerve) in the phase effect mechanism. Methods: Four normal hearing and four sensorineural hearing loss subjects were recruited. Schroeder-phase masking test was conducted at $500 \mathrm{~Hz}, 1 \mathrm{kHz}$, and $2 \mathrm{kHz}(75 \mathrm{~dB} \mathrm{~A})$, and phase effect was recorded. Electrocochleography (ECochG) test via tip-trode recording using $90 \mathrm{dBnHL}$ tone burst at 500 $\mathrm{Hz}, 1 \mathrm{kHz}$, and $2 \mathrm{kHz}$ was also conducted on the same subjects. The amplitude of three ECochG components; i) cochlear microphonic (CM) - arises from outer hair cells, ii) summating potential (SP) - arises from inner hair cells, and iii) action potential (AP)- arises from auditory nerve; were recorded. Pearson and Spearman analysis were performed to find correlation between phase effect and individual ECochG components' amplitude. Results: Result showed no significant correlation between phase effect and all ECochG components' amplitude at all tested frequencies with exception at $2 \mathrm{kHz}$. A significant strong correlation ( $\mathrm{p}$ : 0.02; $\mathrm{r}$ : 0.81 ) between phase effect and action potential's amplitude at $2 \mathrm{kHz}$ was observed. Conclusions: This finding suggests that central auditory function (i.e. auditory nerve) is possibly involved in the phase effect mechanism. This finding gives new insight towards better understanding of auditory perception.

KEYWORDS: Schroeder-phase masking; phase effect mechanism; Electrocochleography 